\title{
Cox-2 gene overexpression in ureteral stump urothelial carcinoma following nephrectomy for renal cell carcinoma: a case report
}

\author{
Wei-Pin Chang ${ }^{1}$, Tsu-Ming Chien², Yu-Shiuan Wang ${ }^{3}$, Siou-Jin Chiư ${ }^{3}$, Mei-Hui Lee ${ }^{4}$, Wei-Chiao Chang ${ }^{2,5}$, \\ Yii-Her Chou ${ }^{4,6^{*}}$ and Ming-Feng $\mathrm{Hou}^{5}$
}

\begin{abstract}
Introduction: A primary ureteral stump tumor after a nephrectomy is rare; urothelial carcinoma of the ureteral stump after a nephrectomy for renal cell carcinoma is even rarer. A thorough review of the literature indicated that only seven cases have previously been reported. In this study, we report the first Taiwanese case of urothelial carcinoma of the ureteral stump after a nephrectomy. It is also the first female case in the literature. The relationship between inflammatory genes, medication history and ureteral stump carcinoma after a nephrectomy for renal cell carcinoma has not been reported.
\end{abstract}

Case presentation: A 72-year-old Asian Taiwanese women with chronic hepatitis C, liver cirrhosis and chronic kidney disease underwent a hand-assisted laparoscopic radical nephrectomy in 2001 due to renal cell carcinoma. Nine years later, she was diagnosed with ureteral stump urothelial carcinoma. Genetic and medication surveys were performed. Importantly, our patient had taken Chinese herbal drugs for more than 10 years and the inflammatory gene, Cox-2, was highly expressed in this patient. This is the first report to study the relationship between the Cox-2 gene and ureteral stump carcinoma after a nephrectomy for renal cell carcinoma.

Conclusion: Long-term multiple use of Chinese herbal drugs could be one of the important risk factors for developing urothelial cancer. Close functional coupling between Chinese herbal drugs, Cox-2 gene activation and urothelial cancer should be further investigated.

\section{Introduction}

The incidence of urothelial carcinoma in the ureter is rare, accounting for less than $5 \%$ of all urothelial neoplasms. It often occurs in the lower third of the ureter and the recurrence rate is relatively high [1]. A primary tumor of the ureteral stump after a nephrectomy is infrequently observed. Moreover, a primary tumor of the ureteral stump after a nephrectomy for a renal cell carcinoma (RCC) is extremely rare. A thorough review of the literature indicated that only seven cases have previously been reported of ureteral stump carcinoma after a nephrectomy for an RCC [2-8]. This eighth observed case is the first reported case in Taiwan.

\footnotetext{
* Correspondence: yihech@gap.kmu.edu.tw

${ }^{4}$ Department of Urology, Kaohsiung Medical University Hospital, Taiwan
}

Full list of author information is available at the end of the article
Prostaglandins are important inflammatory molecules involved in the pathogenesis of cancer. Prostaglandins can be metabolized from arachidonic acid by the cyclooxygenases 1 (Cox-1) and cyclooxygenases 2 (Cox-2). Cox-1 is a constitutive enzyme whereas Cox-2 is an inducible enzyme that is activated by extracellular stimulations including cytokines [9], growth factors [10] and endotoxins [11]. Several lines of evidence indicate that Cox-2 is one of the most critical enzymes in tumor metastasis. Cox-2 overexpression may lead to the cancer cell invasiveness of human breast cancer cells [12]. Clinical studies have extensively documented that Cox-2 inhibitors, such as nonsteroidal anti-inflammatory drugs, can reduce the incidence of colon cancer [13].

To the best of our knowledge, the relationship between inflammatory genes, medication history and ureteral stump carcinoma after a nephrectomy for an RCC has not been reported. We therefore conducted a prospective

\section{C) Biomed Central}


study to identify the potential risk factor in the first reported case of ureteral stump carcinoma after a nephrectomy for an RCC in Taiwan.

\section{Case presentation}

A 72-year-old Asian Taiwanese woman with intermittent, painless, total gross hematuria visited the Department of Urology of our hospital in 2010. She had been diagnosed with chronic hepatitis C and stage III chronic kidney disease for 10 years and has regular follow-up. In 2001 (nine years ago), a routine ultrasound examination showed a left renal tumor. Computed tomography (CT) confirmed the diagnosis (Figure 1). She then was transferred to our Department of Urology and underwent a hand-assisted laparoscopic radical nephrectomy. The pathological reports revealed an RCC of stage T1N1M0, which covered the cortex and medulla with central areas of necrosis and hemorrhage, measuring $11.0 \mathrm{~cm} \times 7.0 \mathrm{~cm} \times$ $4.0 \mathrm{~cm}$. The calyx segment of the collecting system was also included. Her ureter was not dilated and its mucosa was not remarkable. Fortunately, her ureter was free from cancer tissues. After the operation, she received regular follow-up.

At the beginning of 2010, nine years later, our patient had one episode of gross hematuria. The results of examinations such as urine cytology and cystoscopy were normal. A CT scan showed two renal stones in her right kidney without other abnormalities. The hematuria subsided spontaneously. Two months later, another episode of gross hematuria occurred. This time, clot formation was noted in her urine. Once again, the symptoms subsided spontaneously. Cystoscopy revealed whitish debris coating the left ureter orifice; no gross bladder tumor was seen. A ureter catheter could not be inserted into her left ureter due to a ureterovesical junction stricture. Thus, retrograde pyelography with a cone tip ureteral catheter was tried, but also failed. However, CT scans showed a prominent soft tissue mass at the ureterovesical junction. The middle and lower third parts of her residual left ureter were dilated (Figure 2). According to the imaging, a urothelial carcinoma of the ureter stump was highly suspected. Therefore, a ureteroscopic examination and biopsy was performed using a fiberoptic rigid ureteroscope. We tried to use a guidewire to pass the ureteral orifice cystoscopically but the guidewire could only be progressed for less than $1 \mathrm{~cm}$. The ureteroscope was therefore inserted without intramural dilatation of the ureterovesical junction and it was only possible to examine the ureter up to less than $1 \mathrm{~cm}$ from the ureterovesical junction. The biopsy was thus taken from the lower ureter where it is close to the ureterovesical junction. The pathological report showed a high-grade infiltrating urothelial carcinoma. The tumor invaded the subepithelial connective tissue (lamina propria) and the pathologic staging of the primary tumor was T1. A radical operation (ureterectomy with ipsilateral bladder cuff excision or a cystectomy) or systemic chemotherapy were suggested. Without family support, our patient had been in a depressed state for a long time. With consideration of the multiple coexisting systemic diseases, such as liver cirrhosis, chronic kidney disease, gallbladder stones, facial palsy, hypertension and

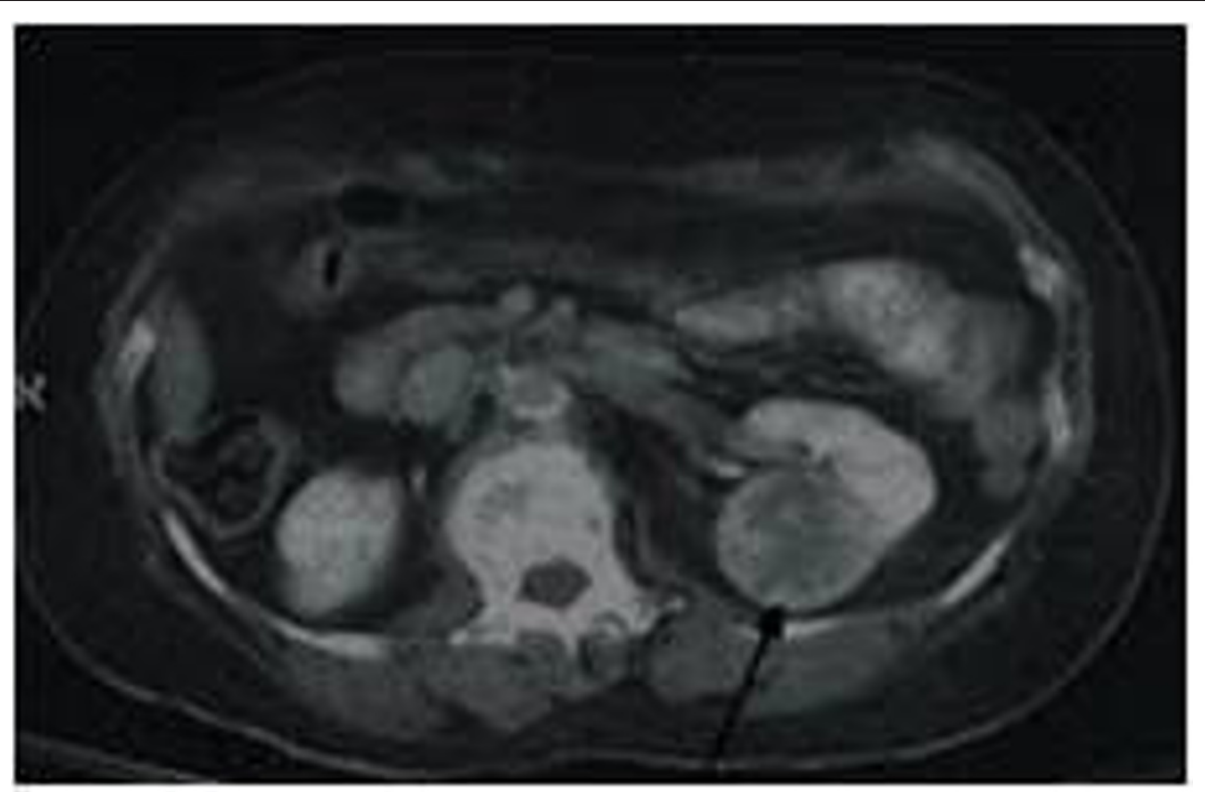

Figure 1 Axial view of contrast-enhanced computed tomography scans revealing a left renal tumor. 


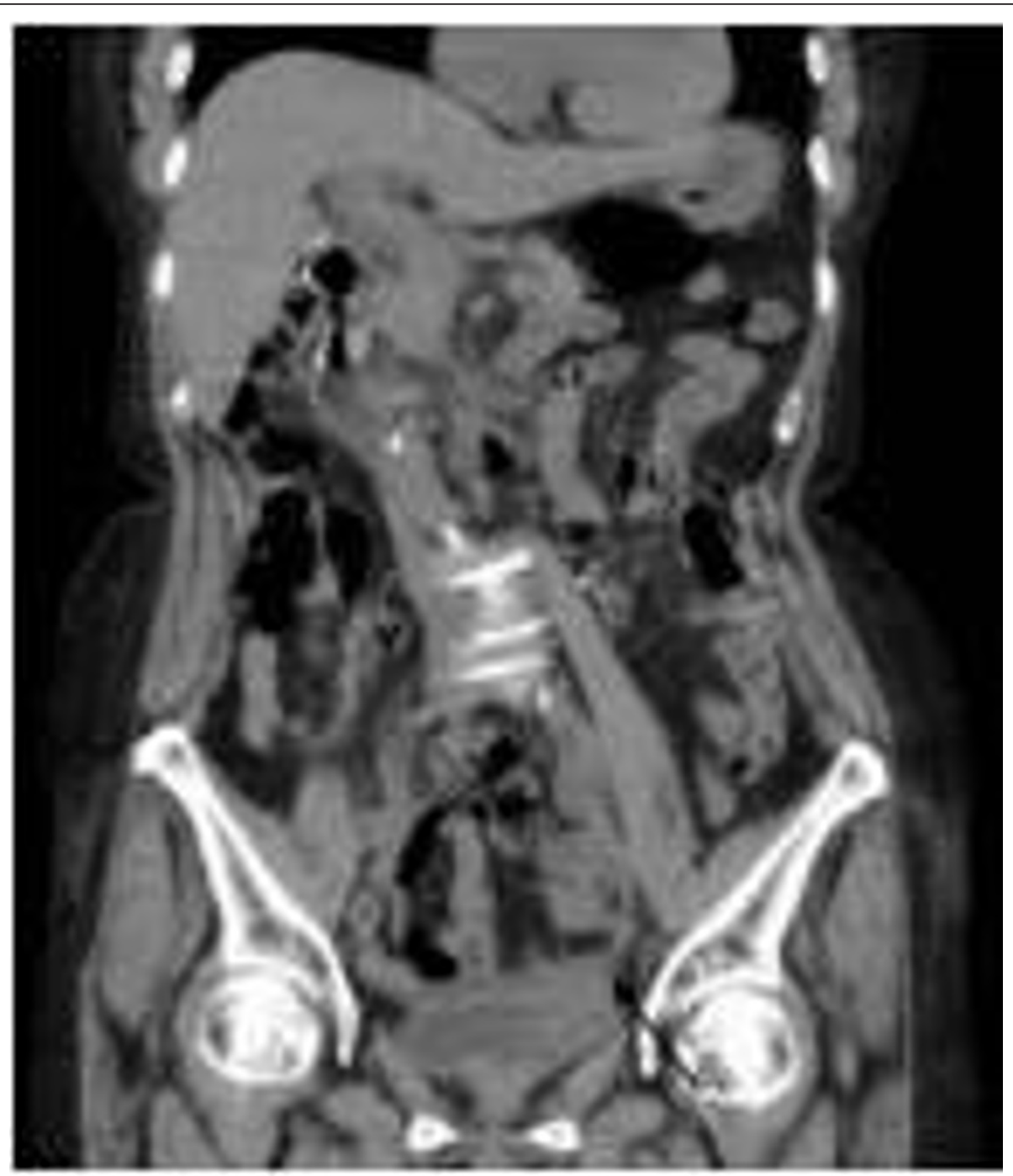

Figure 2 Coronal view of computed tomography scans revealing a prominent soft tissue at the left ureterovesical junction. The middle and lower third parts of her residual ureter were dilated.

recurrent urinary tract infection, our patient refused both treatment options. She asked for supportive treatment only.

To further identify the possible risk factors contributing to the urothelial carcinoma of the ureteral stump, we checked the medication history of our patient. As shown in Table 1, our patient had taken several different kinds of drugs for more than 10 years. These were cephalosporin, nitroxoline, sulfonamide, levofloxacin for urinary tract infection, atenolol, amlodipine, solantin for hypertension, atorvastatin for hyperlipidemia, ursodeoxycholic acid for liver cirrhosis and Chinese herbal drugs for multiple somatic complaints. Importantly, although our patient had taken Chinese herbal drugs for more than 10 years, the compositions of these drugs remain unclear. Long-term multiple use of Chinese herbal drugs may influence inflammatory reactions. We therefore compared gene expression level of Cox-2 between this patient and patients with calcium nephrolithiasis. Real-time polymerase chain reaction experiments indicated that a high level of expression of the Cox-2 gene was seen in our patient with the urothelial carcinoma of the ureteral stump (Figure 3).

\section{Discussion}

An RCC is a common renal parenchymal malignant tumor. RCCs originate from the proximal renal tubular epithelium in the renal cortex. Urothelial carcinoma is a common cancer of the urinary bladder. It may also occur in the collecting system of the upper urinary tract, such as the renal pelvis and ureter. The causes of RCCs are unknown; environmental exposure to asbestos, solvents 
Table 1 Medication history and the possible side effects

\begin{tabular}{lll}
\hline Drug & Disease/disturbance & Side effect \\
\hline Cefradine & Urinary tract infection & Hypersensitivity, elevated liver enzyme, diarrhea \\
Nitroxoline & Urinary tract infection & Gastrointestinal intolerance, urine coloration \\
Sulfonamide & Urinary tract infection & Hypersensitivity, folic acid deficiency, hematological abnormality \\
Levofloxacin & Urinary tract infection & Diarrhea, tendinitis, seizure neuropathy, elevated liver enzyme \\
Atenolol & Hypertension & Bradycardia, cough, Raynaud's syndrome \\
Amlodipine & Hypertension & Flush, tachycardia, edema \\
Solantin & Thromboembolism & Dizziness, abdomen distress, angina, headache \\
Ursodeoxycholic acid & Liver cirrhosis & Gastrointestinal disturbance \\
Atorvastatin & Hyperlipidemia & Gastrointestinal disturbance, elevated liver enzyme, myopathy, neuropathy \\
Chinese herb drugs & Multiple somatic complaints & Unknown \\
\hline
\end{tabular}

and cadmium, smoking and genetic mutation have been implicated. The causes of urothelial cancer include smoking and occupational exposure to chemicals, dyes, rubbers, petroleum, leathers and printing materials; people who are exposed to these for a long time are a high-risk group for developing urothelial cancers. Genetic changes may also occur throughout the urothelium.
A primary ureteral stump tumor can be defined as a tumor occurring in the closed ureteral stump after a nephrectomy for either benign or malignant disease other than a urothelial tumor. Clinically, both diagnoses and treatments for a ureteral stump tumor are still elusive. Furthermore, a primary urothelial carcinoma of the ureteral stump after a nephrectomy for an RCC is

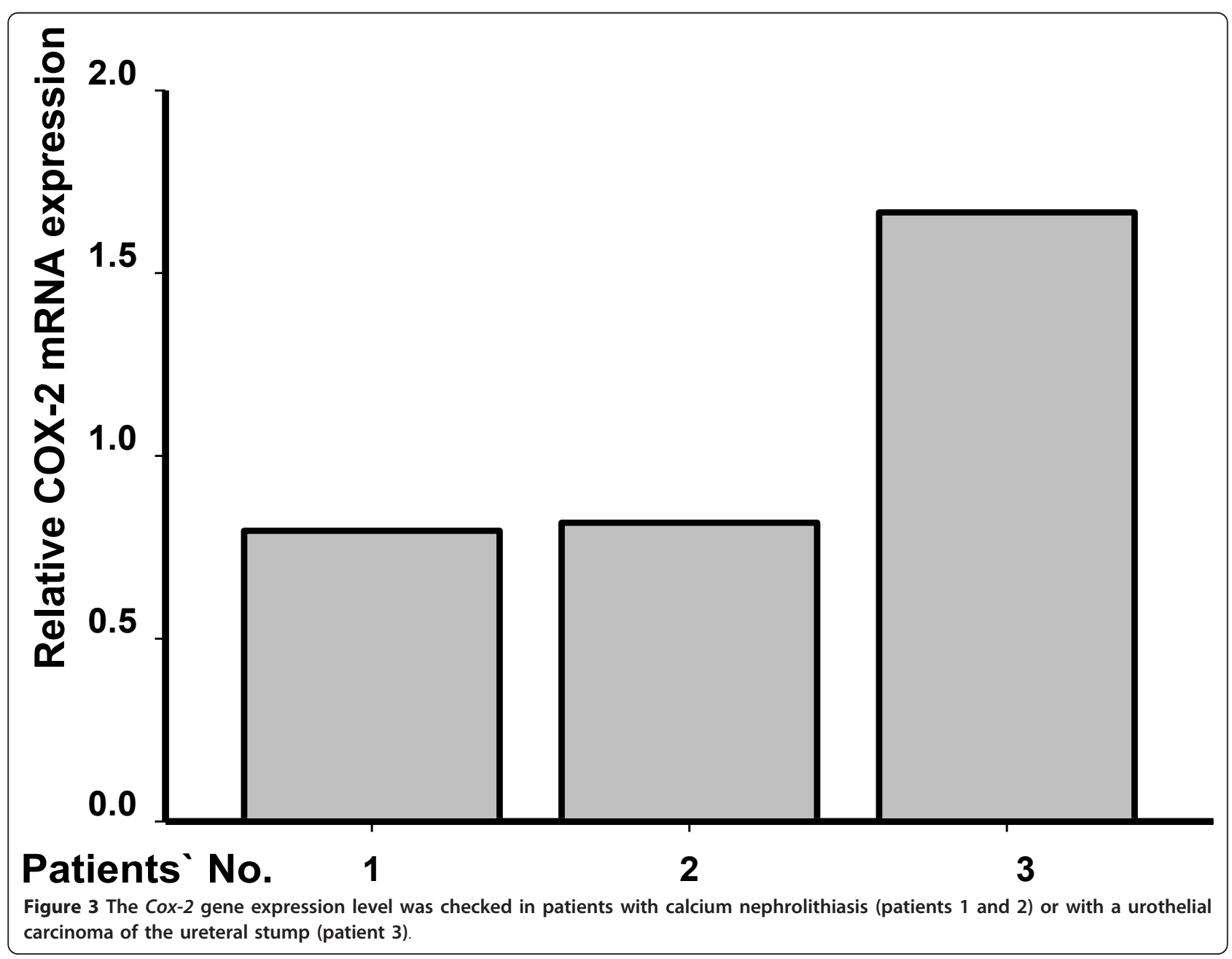


extremely rare. Only seven cases were reported in the literature (Table 2). Our case is the first case in Taiwan and is the first female case in the literature.

In the reported cases, the mean interval between the nephrectomy and detection of the ureteral stump tumor was $7.1 \pm 7.0$ years, ranging from 0.9 years to 23 years. In a report by Kim et al., the interval between the detection of a ureteral stump tumor and the nephrectomy for benign renal disease was 76.5 months [14]. Although the etiology of a ureteral stump tumor remains to be seen, metaplastic changes caused by chronic inflammation due to infection or stone irritation, malignant metamorphosis caused by leukoplakia [15], exposure to carcinogenic substances, a high risk of genetic cancer susceptibility and several others factors are very likely to be associated with this rare disease. Chronic inflammation is often related to squamous cell metaplasia resulting in squamous cell carcinoma [16]. After a nephrectomy, the ureteral stump is no longer exposed to the chemical carcinogens which are present in the urine; resulting in a low possibility of developing cancer from a urinary carcinogen. Genetic hypersensitivity, mutation or pharmacological carcinogenetic effects provide other possibilities for cancer development. Our patient had experienced chronic recurrent urinary tract infection, with episodes occurring three to four times every year. Several reports have indicated the correlation between Chinese herbal drugs and urothelial carcinoma [17-20]. A patient with liver cirrhosis, such as ours, may have a reduced ability to metabolize herbal drugs due to damage to the liver. Therefore, the side effects of Chinese herbal drugs may be amplified and accumulate.

In addition to chemical carcinogenesis from Chinese herbal drugs, genetic effects might contribute to malignant tumors. Cox-2 polymorphism has been shown to be a predictive marker of survival in non-small cell lung cancer patients treated with chemoradiotherapy or radiotherapy $[19,21,22]$. Our results, consistent with previous reports, indicated that a high level of Cox-2 gene expression may

Table 2 Patient data for a ureteral stump tumor after a nephrectomy for a renal cell carcinoma

\begin{tabular}{llllll}
\hline Case & Age & Sex & $\begin{array}{l}\text { Interval } \\
\text { (years) }\end{array}$ & Side & Reference \\
\hline 1 & 75 & M & Two and a half & Right & {$[4]$} \\
2 & 62 & M & Two and a half & Right & {$[5]$} \\
3 & 70 & M & Seven & Right & {$[3]$} \\
4 & 49 & M & 23 & Left & {$[2]$} \\
5 & 88 & M & Six & Left & {$[6]$} \\
6 & 64 & M & Six & Right & {$[8]$} \\
7 & 68 & M & 0.9 & Right & {$[7]$} \\
8 & 72 & F & Nine & Left & Present case \\
\hline
\end{tabular}

be associated with the pathogenesis of the primary ureteral stump tumor. The Cox-2 gene can be evoked by a variety of chemical compounds, including alkaloids, polysaccharides and heavy metals. Chinese herbal drugs contain a large amount of alkaloids, polysaccharides and heavy metals. Long-term use of Chinese herbal drugs may result in physiological dysfunction. Another postulation by Klee and colleagues [5] was that a prior bladder carcinoma could make reflux implantation into the ureteral stump more likely, even though no significant vesicoureteral reflux was noted. In other words, a history of previous cancer elsewhere in the urinary tract was thought to be a high risk factor for ureteral stump cancer. Unlike the assumption proposed by Klee and colleges, the patient in our case had no history of bladder cancer, but her ureteral stump had possibly been exposed to urinary carcinogens for more than 10 years because of vesicoureteral reflux.

\section{Conclusions}

Urothelial carcinoma of the ureteral stump after a nephrectomy for an RCC is rare. A ureteral excision made during a nephrectomy should be as large as possible for benign disease or a non-urothelial tumor. If the ureter is left after the nephrectomy, the ureteral stump should be evaluated and followed-up carefully. Longterm multiple use of Chinese herbal drugs could be one of the important risk factors for developing urothelial cancer. Close functional coupling between Chinese herbal drugs, Cox-2 gene activation and urothelial cancer should be further investigated.

\section{Consent}

Oral and written informed consent was obtained from the patient and her next-of-kin for publication of this case report and any accompanying images. A copy of the written consent is available for review by the Editorin-Chief of this journal.

\section{Acknowledgements}

This study was supported by funding from an Excellence for Cancer Research Center grant, Department of Health, Executive Yuan, Taiwan, R.O.C. (DOH101-TD-C-111-002)

\footnotetext{
Author details

'Department of Healthcare Management, Yuanpei University, HsinChu, Taiwan. ${ }^{2}$ School of Post-baccalaureate Medicine, Kaohsiung Medical University, Taiwan. ${ }^{3}$ Department of Medical Genetics, Kaohsiung Medical University, Taiwan. ${ }^{4}$ Department of Urology, Kaohsiung Medical University Hospital, Taiwan. ${ }^{5}$ Cancer center, Kaohsiung Medical University Hospital, Kaohsiung, Taiwan. ${ }^{6}$ Department of Urology, Kaohsiung Medical University, Taiwan.

Authors' contributions

WPC drafted the article. WPC, TMC and YSW analyzed and interpreted the patient data. MHL photographed and interpreted the pathologic findings. WCC, MFH, WPC and SJC took part in the critical revision and YHC took part in the diagnosis, treatment of the patient and gave final approval of the manuscript. All authors have made substantive intellectual contributions to
} 
this study and to the manuscript and have read and approved the final manuscript.

\section{Competing interests}

The authors declare that they have no competing interests.

Received: 26 October 2011 Accepted: 30 January 2012

Published: 30 January 2012

\section{References}

1. Pohar KS, Sheinfeld J: When is partial ureterectomy acceptable for transitional-cell carcinoma of the ureter? J Endourol 2001, 15:405-408, discussion 409

2. Cher ML, Milchgrub S, Sagalowsky Al: Transitional cell carcinoma of the ureteral stump 23 years after radical nephrectomy for adenocarcinoma. J Urol 1993, 149:106-108.

3. Gohji K, Ueno K, Higuchi A, Fujii A: A case of asynchronous renal cell carcinoma and urothelial cancer of the urinary bladder and left ureter. Hinyokika Kiyo 1993, 39:927-930.

4. Grey LF, Sorial RF, Levin HJ: Transitional cell carcinoma in ureteral stump after radical nephrectomy for renal cell carcinoma. Urology 1987, 29:209-210.

5. Klee LW, Adams MC, Foster RS: Ureteral stump transitional cell carcinoma in a patient with recurrent superficial bladder cancer: an argument for complete nephroureterectomy in selected patients. J Urol 1990, 144:972-973.

6. Mitsui K, Yamada Y, Taki T, Akahori M, Kato K, Honda N, Fukatsu H, Kawai Y, Yoshikawa K: A case of asynchronous renal cell carcinoma, hepatocellular carcinoma and residual ureteral cancer. Hinyokika Kiyo 1998, 44:583-586.

7. Nagatsuma K, Tachibana M, Miyakawa A, Asanuma H, Murai M: Transitional cell carcinoma of ureteral stump after radical nephrectomy for renal cell carcinoma. Int J Urol 1999, 6:627-629.

8. Suzuki T, Tsuchiya N, Otomo R, Kakinuma H, Satoh S, Sato K, Ogawa O, Kato T: Primary tumor of the ureteral stump following a nephrectomy for renal cell carcinoma. Int J Urol 1999, 6:41-43.

9. Jones DA, Carlton DP, Mclntyre TM, Zimmerman GA, Prescott SM: Molecular cloning of human prostaglandin endoperoxide synthase type II and demonstration of expression in response to cytokines. J Biol Chem 1993, 268:9049-9054

10. Chen LC, Chen BK, Chang JM, Chang WC: Essential role of c-Jun induction and coactivator p300 in epidermal growth factor-induced gene expression of cyclooxygenase-2 in human epidermoid carcinoma A431 cells. Biochim Biophys Acta 2004, 1683:38-48.

11. Hla T, Neilson K: Human cyclooxygenase-2 cDNA. Proc Natl Acad Sci USA 1992, 89:7384-7388.

12. Singh B, Berry JA, Shoher A, Ramakrishnan V, Lucci A: COX-2 overexpression increases motility and invasion of breast cancer cells. Int J Oncol 2005, 26:1393-1399.

13. Hyde CA, Missailidis S: Inhibition of arachidonic acid metabolism and its implication on cell proliferation and tumour-angiogenesis. Int Immunopharmacol 2009, 9:701-715.

14. Kim YJ, Jeon SH, Huh JS, Chang SG: Long-term follow-up of ureteral stump tumors after nephrectomy for benign renal disease. Eur Urol 2004 46:748-752.

15. Park JY, Park J, Ku JH, Kim HH: Transitional cell carcinoma in a remnant ureter after retroperitoneoscopic simple nephrectomy for benign renal disease. J Korean Med Sci 2009, 24:992-994.

16. Holmang S, Lele SM, Johansson SL: Squamous cell carcinoma of the renal pelvis and ureter: incidence, symptoms, treatment and outcome. J Urol 2007, 178:51-56.

17. Cheung TP, Xue C, Leung K, Chan K, Li CG: Aristolochic acids detected in some raw Chinese medicinal herbs and manufactured herbal products-a consequence of inappropriate nomenclature and imprecise labelling? Clin Toxicol (Phila) 2006, 44:371-378.

18. Mason RG, Donaldson D: Chinese herbal nephropathy and urothelial malignancy. J R Soc Promot Health 2002, 122:266-267.

19. Nortier JL, Martinez MC, Schmeiser HH, Arlt VM, Bieler CA, Petein M Depierreux MF, De Pauw L, Abramowicz D, Vereerstraeten P, Vanherweghem JL: Urothelial carcinoma associated with the use of a Chinese herb (Aristolochia fangchi). N Engl J Med 2000, 342:1686-1692.
20. Shum S: Chinese herbs and urothelial carcinoma. N Engl J Med 2000, 342:1686-1692.

21. Bi N, Yang $M$, Zhang $L$, Chen $X$, Ji W, Ou G, Lin D, Wang L: Cyclooxygenase- 2 genetic variants are associated with survival in unresectable locally advanced non-small cell lung cancer. Clin Cancer Res 2010, 16:2383-2390.

22. Grimminger PP, Stöhlmacher J, Vallböhmer D, Schneider PM, Hölscher AH, Metzger R, Danenberg PV, Brabender J: Prognostic significance and clinicopathological associations of COX-2 SNP in patients with nonsmall cell lung cancer. J Oncol 2009, 2009:139590.

doi:10.1186/1752-1947-6-44

Cite this article as: Chang et al: Cox-2 gene overexpression in ureteral stump urothelial carcinoma following nephrectomy for renal cell carcinoma: a case report. Journal of Medical Case Reports 2012 6:44.

\section{Submit your next manuscript to BioMed Central and take full advantage of:}

- Convenient online submission

- Thorough peer review

- No space constraints or color figure charges

- Immediate publication on acceptance

- Inclusion in PubMed, CAS, Scopus and Google Scholar

- Research which is freely available for redistribution

Submit your manuscript at www.biomedcentral.com/submit
Ciomed Central 